\title{
Screening for differentially expressed genes in Anoectochilus roxburghii (Orchidaceae) during symbiosis with the mycorrhizal fungus Epulorhiza sp.
}

\author{
LI Biao $^{1,2 \dagger}$, TANG MingJuan ${ }^{1 \dagger}$, TANG Kun $^{1}$, ZHAO LiFang $^{1} \&$ GUO ShunXing ${ }^{1 *}$ \\ ${ }^{1}$ Center of Biotechnology, Institute of Medicinal Plant Development, Chinese Academy of Medical Sciences, Beijing 100193, China; \\ ${ }^{2}$ College of Bioinformation, Chongqing University of Posts \& Telecommunications, Chongqing 400065, China
}

Received July 24, 2011; accepted August 21, 2011

\begin{abstract}
Mycorrhizal fungi promote the growth and development of plants, including medicinal plants. The mechanisms by which this growth promotion occurs are of theoretical interest and practical importance to agriculture. Here, an endophytic fungus (AR-18) was isolated from roots of the orchid Anoectochilus roxburghii growing in the wild, and identified as Epulorhiza sp. Tissue-cultured seedlings of $A$. roxburghii were inoculated with AR-18 and co-cultured for $60 \mathrm{~d}$. Endotrophic mycorrhiza formed and the growth of $A$. roxburghii was markedly promoted by the fungus. To identify genes in A. roxburghii that were differentially expressed during the symbiosis with AR-18, we used the differential display reverse transcription polymerase chain reaction (DDRT-PCR) method to compare the transcriptomes between seedlings inoculated with the fungus and control seedlings. We amplified 52 DDRT-PCR bands using 15 primer combinations of three anchor primers and five arbitrary primers, and nine bands were re-amplified by double primers. Reverse Northern blot analyses were used to further screen the bands. Five clones were up-regulated in the symbiotic interaction, including genes encoding a uracil phosphoribosyltransferase (UPRTs; EC 2.4.2.9) and a hypothetical protein. One gene encoding an amino acid transmembrane transporter was down-regulated, and one gene encoding a tRNA-Lys (trnK) and a maturase K (matK) pseudogene were expressed only in the inoculated seedlings. The possible roles of the above genes, especially the UPRTs and matK genes, are discussed in relation to the fungal interaction. This study is the first of its type in A. roxburghii.
\end{abstract}

\begin{abstract}
Anoectochilus roxburghii, orchid mycorrhizal symbiosis, Epulorhiza sp., differential display-PCR (DD-PCR), gene screening
\end{abstract}

Citation: $\quad$ Li B, Tang M J, Tang K, et al. Screening for differentially expressed genes in Anoectochilus roxburghii (Orchidaceae) during symbiosis with the mycorrhizal fungus Epulorhiza sp.. Sci China Life Sci, 2012, 55: 164-171, doi: 10.1007/s11427-012-4284-0

Anoectochilus roxburghii (Orchidaceae) is a phanerophyte that grows in humus soils in misty and humid broad-leaved forests [1]. This plant was originally used as a source of the precious natural drugs known as 'King Medicine' in China. Extracts from this plant have diverse pharmacological effects, such as liver protection, cancer prevention, antioxidant activities, and anti-inflammatory effects [2]. It has been

\footnotetext{
$\dagger$ Contributed equally to this work

* Corresponding author (email: sxguo2006@yahoo.com.cn)
}

widely used as a folk medicine to treat cancers and cardiovascular, lung, and liver diseases, and it is given to underdeveloped children in China and other Asian countries [3].

A. roxburghii is now facing extinction because of destruction of its habitat, combined with heavy exploitation of its wild resources, its low propagation rate, and its slow growth [4]. All members of the Orchidaceae are symbiotic with fungi under field conditions [5,6]. In the field, wild $A$. roxburghii commonly forms mycorrhizal symbiotic relationships with some endophytic fungi. Therefore, screening 
for beneficial fungi that promote the growth and development of $A$. roxburghii, and studying the plant-fungus interaction is of great theoretical significance, and will help to preserve this germplasm resource through the development of new progenitive approaches [7].

In our previous work, an endophytic fungus, AR-18, a species of Epulorhiza, was successfully isolated from the roots of wild-grown $A$. roxburghii [8]. When seedlings of $A$. roxburghii were inoculated with Epulorhiza sp. AR-18 in vitro, they showed a promotion in growth, increased survival rate and yield, increased activities of four enzymes [9], a greater number of buds and roots per plant [10], and increased contents of polysaccharides and flavones [5,11]. These results indicate that some genes in A. roxburghii are differentially expressed in plant-fungus symbioses. In this study, we searched for genes with altered expression in the presence of the endophytic fungus.

To identify and isolate differentially expressed genes, several techniques based on the polymerase chain reaction (PCR) can be used [12,13]. Differential display reverse transcription (DDRT)-PCR can identify novel transcripts by comparative analysis of more than two samples. Therefore, integrating DDRT-PCR and microarray analysis should provide a more comprehensive approach to understand the molecular mechanisms of the symbiosis between medicinal plants and fungi [14,15]. Furthermore, DDRT-PCR has several advantages over other methods: the techniques are fast, simple, and widely accessible; it sensitively detects low-abundance mRNA transcripts and requires only small amounts of RNA; both induced and repressed genes can be detected simultaneously, and more than two samples can be compared [16]. The objective of this study was to identify genes that are differentially expressed in A. roxburghii during its mycorrhizal symbiosis using a differential display technique $[14,17,18]$. Comparative molecular studies will provide information that will increase our understanding of the mechanism by which an endophytic fungus improves the growth and development of $A$. roxburghii.

\section{Materials and methods}

\subsection{Plant materials}

Seedlings from the same clone of $A$. roxburghii were grown on improved MS medium [19], which was supplemented with $10 \%(\mathrm{w} / \mathrm{v})$ active carbon, $3 \%(\mathrm{w} / \mathrm{v})$ sucrose, and $0.8 \%$ $(\mathrm{w} / \mathrm{v})$ agar, $\mathrm{pH}$ 5.8. Seedlings were grown in a conventional greenhouse with a 12-h light/12-h dark photoperiod at $(24 \pm 1)^{\circ} \mathrm{C}$, and an illumination intensity of $2000 \mathrm{Lx}$.

\subsection{Culturing and identification of the endophytic fungus}

The representative strain (No. AR-18) was stored at low temperatures $\left(0-4{ }^{\circ} \mathrm{C}\right)$ at the Institute of Medicinal Plant
Development, Chinese Academy of Medical Sciences \& Peking Union Medical College. The strain was inoculated on a plate of wheat bran medium, consisting of $30 \mathrm{~g} \mathrm{dm}^{-3}$ wheat bran, $1.5 \mathrm{~g} \mathrm{dm}^{-3} \mathrm{MgSO}_{4}, 3 \mathrm{~g} \mathrm{dm}^{-3} \mathrm{KH}_{2} \mathrm{PO}_{4}, 20 \mathrm{~g}$ $\mathrm{dm}^{-3} \mathrm{D}$-glucose, and $14 \mathrm{~g} \mathrm{dm}^{-3}$ agar. Before inoculation, the fungus was activated by culturing for $10-15 \mathrm{~d}$ at $(24 \pm 1)^{\circ} \mathrm{C}$ in the dark. Discs were excised from the medium using a hole puncher $(\Phi 11 \mathrm{~mm})$, and were then used as the inocula. The mycelia of the fungal strain were used to prepare water squash slides, which were observed under a light microscope. The fungus was identified as a Epulorhiza species based on the outline of the colonies, formation of concentric rings and aerial hyphae, color of the aerial hyphae, color of the colony centre and its reverse side, thickness and texture of the colony, and the shape and dimension of monilioid cells $[20,21]$.

\subsection{Inoculation of fungi onto $A$. roxburghii roots and their symbiotic structure}

The tissue-cultured seedlings of $A$. roxburghii transplanted on MS medium for $10 \mathrm{~d}$ were co-cultured with the activated Epulorhiza sp. AR-18 at $25^{\circ} \mathrm{C}$. After the seedlings were co-cultured for $60 \mathrm{~d}$, they were harvested and used as the inoculated group. Seedlings grown in the same conditions but without endophytic fungus were used as the control group [22]. When the seedlings were collected, all of the roots were removed, and the remaining tissue was frozen immediately at $-80^{\circ} \mathrm{C}$.

Roots of A. roxburghii co-cultured with Epulorhiza sp. AR-18 for $60 \mathrm{~d}$ were cut into 3-7 mm pieces and fixed immediately in formaldehyde-acetic acid- $50 \%$ alcohol, dehydrated, embedded in paraffin, and sectioned with a microtome. Sections were mounted on slides and heated gently in a water bath and stained with safranin O/fast green (Sigma Chemical Co.) for $10 \mathrm{~min}$. Slides were then rinsed with distilled water and allowed to dry [23]. Stained tissues were viewed and photographed directly using a digital camera.

\subsection{RNA isolation and purification}

Total RNA was isolated from $1 \mathrm{~g}$ stem and leaf tissues from the treated and control group using the improved CTAB method as described by Chang et al. [24]. The RNA yield and quality were measured by determining absorbance at 230, 260, and $280 \mathrm{~nm}$ with a Hitachi 2000 spectrophotometer. RNA quality was checked by RNA gel analysis using a horizontal $1.0 \%$ agarose gel. The gel was visualized and photographed under ultraviolet light after staining with ethidium bromide. The RNA pellets were stored in ethanol at $-80{ }^{\circ} \mathrm{C}$ until use. Total RNA $(20 \mu \mathrm{g})$ was treated with $40 \mathrm{U}$ $\mathrm{RNaseOUT}^{\mathrm{TM}}$ (Invitrogen, USA) and $1 \mathrm{U}$ DNase (Invitrogen) in a solution of $20 \mathrm{mmol} \mathrm{L}^{-1}$ Tris- $\mathrm{HCl}$ ( $\left.\mathrm{pH} 8.4\right), 2$ mmol L ${ }^{-1} \mathrm{MgCl}_{2}$, and $50 \mathrm{mmol} \mathrm{L}{ }^{-1} \mathrm{KCl}$ at room tempera- 
ture for $15 \mathrm{~min}$. Then, $1 \mu \mathrm{L}$ EDTA $\left(25 \mathrm{mmol} \mathrm{L}{ }^{-1}\right)$ was added and the mixture was incubated at $65^{\circ} \mathrm{C}$ for $10 \mathrm{~min}$ to end the reaction.

\subsection{First strand cDNA synthesis and DDRT-PCR}

Complementary DNA was synthesized for $10 \mathrm{~min}$ at room temperature in a $20-\mu \mathrm{L}$ aqueous reaction mixture containing $5.5 \mu \mathrm{L}$ DEPC-treated water, $5 \mu \mathrm{L}(2 \mu \mathrm{g})$ DNA-free total RNA, $4 \mu \mathrm{L} 5 \times$ first strand buffer (Gibco-BRL, Eggenstein, Germany), $0.5 \mu \mathrm{L}$ of $10 \mathrm{mmol} \mathrm{L}^{-1}$ of each dNTP, $2 \mu \mathrm{L} 0.1$ M DTT (Gibco-BRL), $2 \mu \mathrm{L} 20 \mathrm{ng} \mu \mathrm{L}^{-1}$ anchor primer designated $A A G C\left(\mathrm{dT}_{10}\right)-\mathrm{M}$ (where $\mathrm{M}$ is $\mathrm{A}, \mathrm{G}$ or $\mathrm{C}$; Sangon, Shanghai, China), $1 \mu \mathrm{L} 30 \mathrm{U}_{\mu} \mathrm{L}^{-1} \mathrm{RNasin}$ (Sangon) and 1 $\mu \mathrm{L} 200 \mathrm{U} \mu \mathrm{L}^{-1} \mathrm{M}-\mathrm{MLV}$ reverse transcriptase (Gibco-BRL). Then the mixture was incubated at $42^{\circ} \mathrm{C}$ for $50 \mathrm{~min}$ and heated to $48^{\circ} \mathrm{C}$ for $30 \mathrm{~min}$. Following the reaction, the cDNA was incubated at $75^{\circ} \mathrm{C}$ for $10 \mathrm{~min}$ to inactivate the reverse transcriptase, and then stored at $-20^{\circ} \mathrm{C}$ until use.

The polymerase chain reaction (PCR) mixture consisted of $2 \mu \mathrm{L}$ cDNA from the reverse transcription (RT) reaction,

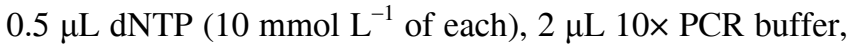
$1.2 \mu \mathrm{L} 25 \mathrm{mmol} \mathrm{L}^{-1} \mathrm{MgCl}_{2}, 2 \mu \mathrm{L}$ arbitrary primer $(20 \mathrm{ng}$ $\mu \mathrm{L}^{-1}$ ), $2 \mu \mathrm{L}$ anchor primer $\mathrm{H}-\mathrm{T}_{10} \mathrm{M}$ (5'-AAGCTTTTTTTTTTM-3', M=A, G or C) (20 ng $\left.\mu \mathrm{L}^{-1}\right)$ and $0.4 \mu \mathrm{L}$ Taq polymerase (Sangon) completed to a volume of $20-\mu \mathrm{L}$ with DEPC-treated $\mathrm{ddH}_{2} \mathrm{O}$. The PCR conditions were as follows: 25 cycles of $94^{\circ} \mathrm{C}$ for $30 \mathrm{~s}, 40^{\circ} \mathrm{C}$ for $2 \mathrm{~min}, 72^{\circ} \mathrm{C}$ for $1 \mathrm{~min}$, followed by 10 cycles of $94^{\circ} \mathrm{C}$ for $30 \mathrm{~s}, 50^{\circ} \mathrm{C}$ for $1 \mathrm{~min}$, $72^{\circ} \mathrm{C}$ for $1 \mathrm{~min}$, and final extension at $72^{\circ} \mathrm{C}$ for $10 \mathrm{~min}$. Prior to PCR, the mixture was heated to $94^{\circ} \mathrm{C}$ for $5 \mathrm{~min}$. Five random primers (DD10, 5'TGCTCCCGGCCGCCAAGC3'; DD20, 5'TGCCGGAATTCTGGTCAT3'; DD23, 5'TGCTCCCGGCCGCCATGG3'; DD34, 5'TGCCGGAATTCTGGTGAC3'; DD60, 5'TGCCGGAATTCCGA- CTGT3'; Sangon) were chosen. A total of 15 primer combinations were screened.

\subsection{Gel electrophoresis and re-amplification}

DDRT-PCR samples were mixed with loading dye (formamide, bromphenol blue, xylene cyanol), denatured at $95^{\circ} \mathrm{C}$ for $10 \mathrm{~min}$, cooled on ice, and loaded onto $6 \%$ polyacrylamide denaturing gels. Gels were run at $60 \mathrm{~W}$ for $4-6 \mathrm{~h}$, and PCR products were detected by silver staining [25-27].

Using a sharp, clean razor blade, the fragments determined to be differentially displayed bands were excised from the gels and soaked in $20 \mu \mathrm{L} \mathrm{ddH_{2 }} \mathrm{O}$ at room temperature for at least $10 \mathrm{~min}$ and then in a water bath at $90-100^{\circ} \mathrm{C}$ for $20 \mathrm{~min}$. After a short centrifugation, the liquid was transferred to a clean Eppendorf tube. The extracted DNA was used directly as the template for PCR [18]. A 4- $\mu \mathrm{L}$ aliquot of the extracted DNA solution was used in a $40-\mu \mathrm{L}$ reaction mixture to reamplify the excised cDNA band. The constituents of the PCR mixtures were identical to those of DD-PCR except for the template. Re-amplification reactions were as follows: $94^{\circ} \mathrm{C}$ for $5 \mathrm{~min}$, then 30 cycles of $94^{\circ} \mathrm{C}$ for $30 \mathrm{~s}, 50^{\circ} \mathrm{C}$ for $1 \mathrm{~min}$, and $72^{\circ} \mathrm{C}$ for $1 \mathrm{~min}$, and a final extension at $72^{\circ} \mathrm{C}$ for $10 \mathrm{~min}$. After reamplification, a $10 \mu \mathrm{L}$ aliquot of the PCR reaction was mixed with $2 \mu \mathrm{L}$ of gel loading dye and separated by electrophoresis on a $1.2 \%$ agarose gel with ethidium bromide to ensure that a fragment of the correct size was amplified.

\subsection{Reverse Northern blot analysis}

A $20-\mu \mathrm{L}$ aliquot of the reamplified products was dotted on each Hybond- $\mathrm{N}^{+}$membrane filter (Amersham Pharmacia, Piscataway, NJ, USA) and used for reverse Northern blotting. The products of reverse transcription were used as probes. The probes were prepared as follows: $10 \mu \mathrm{g}$ RNA treated by DNase I was mixed with $2 \mu \mathrm{L} 20 \mu \mathrm{mol} \mathrm{L}{ }^{-1}$ anchor primer oligo- $\mathrm{dT}_{18}$ and the mixture denatured at $65^{\circ} \mathrm{C}$ for $5 \mathrm{~min}$, rapidly cooled on ice for $2 \mathrm{~min}$, and then added to tubes containing $1 \mu \mathrm{L} 40 \mathrm{U}$ RNaseOUT (Invitrogen), $6 \mu \mathrm{L}$ $5 \times$ First-Strand buffer, $3 \mu \mathrm{L} 0.1 \mathrm{~mol} \mathrm{~L}^{-1}$ DTT, $5 \mu \mathrm{L}$ DIG DNA Labeling Mix (Roche, Mannheim, Germany) and 1 $\mu \mathrm{L}$ Superscript II. The reaction mixture was incubated at $42^{\circ} \mathrm{C}$ for $60 \mathrm{~min}$, then at $48^{\circ} \mathrm{C}$ for $30 \mathrm{~min}$, and finally at $70^{\circ} \mathrm{C}$ for $10 \mathrm{~min}$ to end the reaction. Hybridization and labeling of the cDNA probes were performed as described in the manual of the DIG High Prime DNA Labeling Detection Starter Kit I (Roche).

\subsection{Cloning of differentially displayed cDNAs}

The cDNA fragments confirmed by reverse Northern blot analysis were amplified. The PCR products were extracted from a $0.8 \%$ agarose gel with the DNA Gel Extraction Kit (Yuanpinghao Biotech Co. Ltd., Beijing, China). The extracted cDNA fragment was inserted into a $p G E M-T$ vector (Promega, USA) according to the manufacturer's instructions and cloned into Escherichia coli. Plasmid DNA with the insert was extracted from $E$. coli using the alkaline lysis method [28]. An aliquot $(1-2 \mu \mathrm{L})$ of the extracted plasmid DNA was cut with $0.5 \mu \mathrm{L}$ of the restriction enzyme EcoR I at $50^{\circ} \mathrm{C}$ for $2-4 \mathrm{~h}$ and then incubated at room temperature overnight. The insert was visualized by $1.4 \%$ agarose gel electrophoresis or PCR amplification using the same primer combinations and PCR conditions.

\subsection{DNA sequencing and similarity analysis}

Plasmids were isolated from randomly selected clones using the QIAprep Spin Miniprep kit (Qiagen, Germany). Plasmids were sequenced by the Shanghai Bioasia Biotechnology Co. BLAST searches against sequences in the GenBank databases were conducted to identify DNA sequence homologs. 


\section{Results}

When Epulorhiza sp. AR-18 and the tissue-cultured seedlings of A. roxburghii were co-cultured for 2-3 weeks, the mycelia started to make contact with the roots, whose surfaces gradually changed from a green to a tawny color (Figure 1A). The association with Epulorhiza sp. AR-18 clearly promoted the growth of $A$. roxburghii, as seedlings grown with the fungus for $35 \mathrm{~d}$ showed an average growth increase of $10.3 \%$ compared with control seedlings (data not shown).

Epulorhiza sp. was identified from its morphological characteristics such as colony color, and the shape and dimensions of monilioid cells [29]. On PDA, fungal colonies were white and grew rapidly, reaching $7 \mathrm{~cm}$ in diameter after $5 \mathrm{~d}$ incubation at $25^{\circ} \mathrm{C}$. The hypha were arranged closely, and white aerial hyphae seldom developed. Some of the cultures showed inconspicuous concentric rings (Figure 1B). The hyphae were hyaline, 2-7.5 $\mathrm{mm}$ in diameter, and superficial with a submerged margin. Monilioid cells were barrel-shaped to cylindrical (Figure 1C). These morphological characteristics indicated that the endophytic fungus belonged to the genus Epulorhiza.

The structure of the mychorriza that formed when Epulorhiza sp. AR-18 and A. roxburghii were co-cultured for 60 $\mathrm{d}$ was examined under a light microscope, and its characteristics indicated that it was among the typical mycorrhizae of orchids [30]. The hyphae invaded into the outermost 3-4 layers of cells in the cortical tissue beneath the epidermis. The hyphae consisted of pelotons and mycelial branches in the outer cortical cells, and pelotons and mycelial splinters in the inner cortical cells (Figure 1D). Compared with normal cells, some of the cortical cells showed plasmolysis or an enlarged nucleus.

DDRT-PCR experiments were carried out using a total of 15 DD primer combinations, using tissue samples from plants incubated for $60 \mathrm{~d}$ with the fungus and from the control. After analysis of silver-stained images, 52 differentially expressed bands were selected and excised from the sequencing gel (Figure 2). The selection was based primarily on the presence or absence of a band or on differences in intensity of a particular band between the treated and control samples.

To reamplify the gel-extracted bands, the PCR reaction conditions were altered, and the bands that could be amplified by double primers (anchor primer and random primer) were selected for further study. We did not conduct further analyses on excised bands that could only be amplified by a single anchor primer or a random primer. In total, nine bands that were able to be reamplified by double primers (Figure 3) were excised from the agarose gel, and the DNA
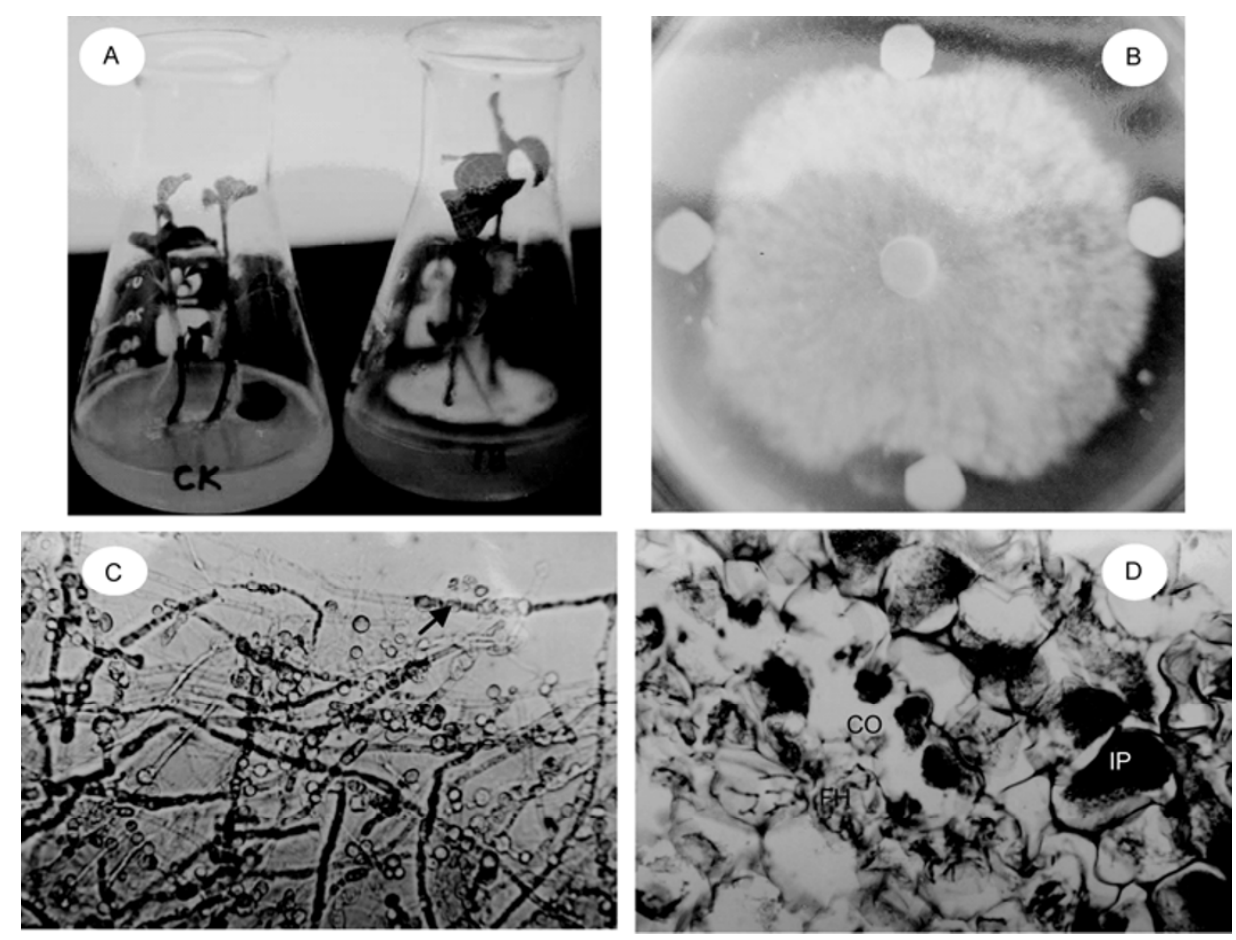

Figure 1 Growth state and structure formed by mycorrhizal Epulorhiza sp. AR-18 associated with tissue-cultured seedlings of Anoectochilus roxburghii co-cultured for $60 \mathrm{~d}$. A, Tissue cultured seedlings inoculated with Epulorhiza sp. AR-18, or uninoculated (control). B, Colony of Epulorhiza sp. AR-18 on PDA after $5 \mathrm{~d}$ at $25^{\circ} \mathrm{C}$. C, Extraradical mycelia of Epulorhiza sp. AR-18 extracted from the mycorrhizosphere of A. roxburghii after $60 \mathrm{~d}$ co-culture. Monilioid cells with slight tubular constriction (arrowhead) (×224). D, Microstructure of symbiosis of A. roxburghii and Epulorhiza sp. AR-18 ( $\times 448)$. IP, intact peloton; $\mathrm{CO}$, cortex cell; $\mathrm{FH}$, fungus hypha. 


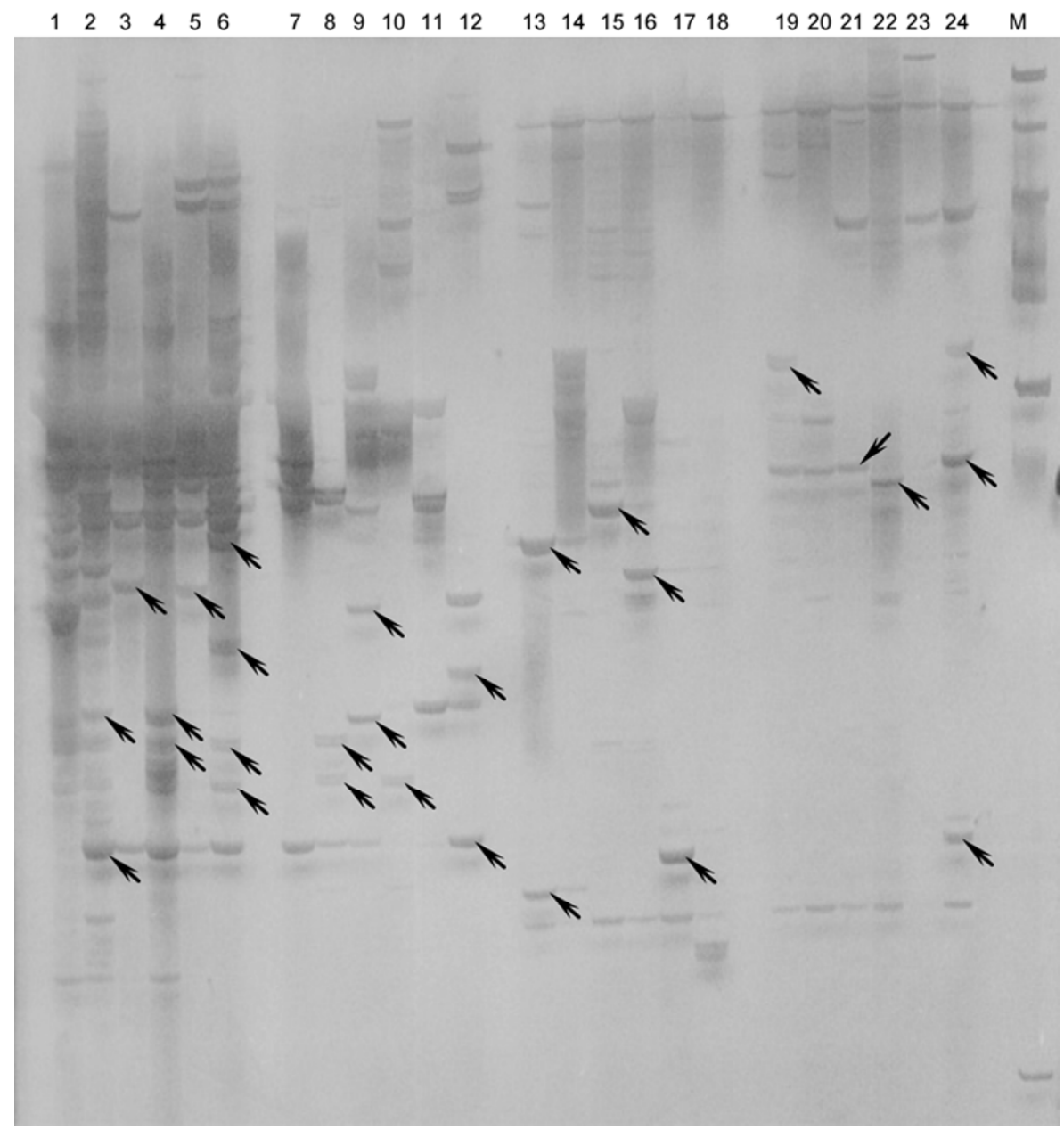

Figure 2 Some differential display band patterns of mRNA from control and fungus-inoculated A. roxburghii. Total RNA extracted from the control (uninoculated) and fungus-inoculated A. roxburghii tissue cultured seedlings was reverse-transcribed and amplified with a 5'-arbitrary primer and a 3 '-anchored primer. Amplified cDNA fragments were separated on a $6 \%$ denaturing polyacrylamide gel. Arrows indicate differentially expressed cDNA fragments that were recovered from the gel and further analyzed. Products from the control are in lanes 1, 3, 5, 7, 9,11,13,15, 17, 19, 21 and 23. Products from the fungus-inoculated seedlings are in lanes $2,4,6,8,10,12,14,16,18,20,22$ and 24. Primer combinations of lanes 1 and 2, 3 and 4,.., 23 and 24 were the same between the two groups. Primer combinations used in lanes 1-8 were $\mathrm{H}-\mathrm{T}_{10} \mathrm{~A}$ and DD10, DD20, DD23, DD34, respectively; lanes 9-16 were H-T $\mathrm{T}_{10} \mathrm{G}$ and DD10, DD20, DD23, DD34, respectively; lanes 17-24 were H-T 10 C and DD10, DD20, DD23, DD34, respectively. M, DNA marker (DL2000).

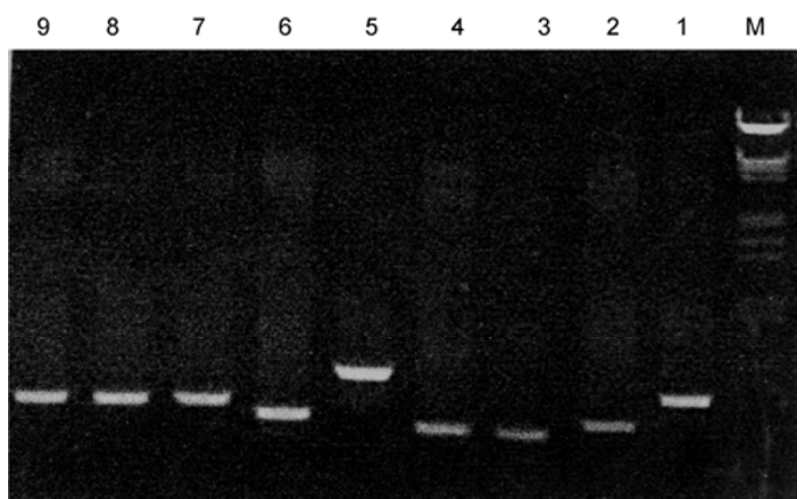

Figure 3 Only the fragments reamplified by double primers of differentially expressed bands were extracted. Lanes 1-9 show differentially expressed bands: AR-DD17, AR-DD19, AR-DD20, AR-DD23, AR-DD44, AR-37, AR-DD47, AR-DD38 and AR-DD40, respectively. M, DNA marker (DL2000). was extracted for use in reverse Northern blot analysis as further confirmation. Seven fragments were confirmed in the reverse Northern blot analysis: AR-DD017, AR-DD019, AR-DD020, AR-DD023, AR-DD037, AR-DD044, and AR-DD047 (Figure 4).

Of those, the genes AR-DD017, AR-DD019, AR-DD037, AR-DD044, and AR-DD047 were up-regulated in A. roxburghii after inoculation with the fungus AR-18. AR-DD020 was down-regulated, and AR-DD023 was expressed only in the treated group. The seven fragments representing differentially expressed genes were cloned into the pGEM-T vector. The clones of the seven fragments were amplified by corresponding primer combinations. Plasmid DNA was extracted from the clones that were confirmed to have target inserts by restriction enzyme digestion.

The above-mentioned seven clones were sequenced, and 

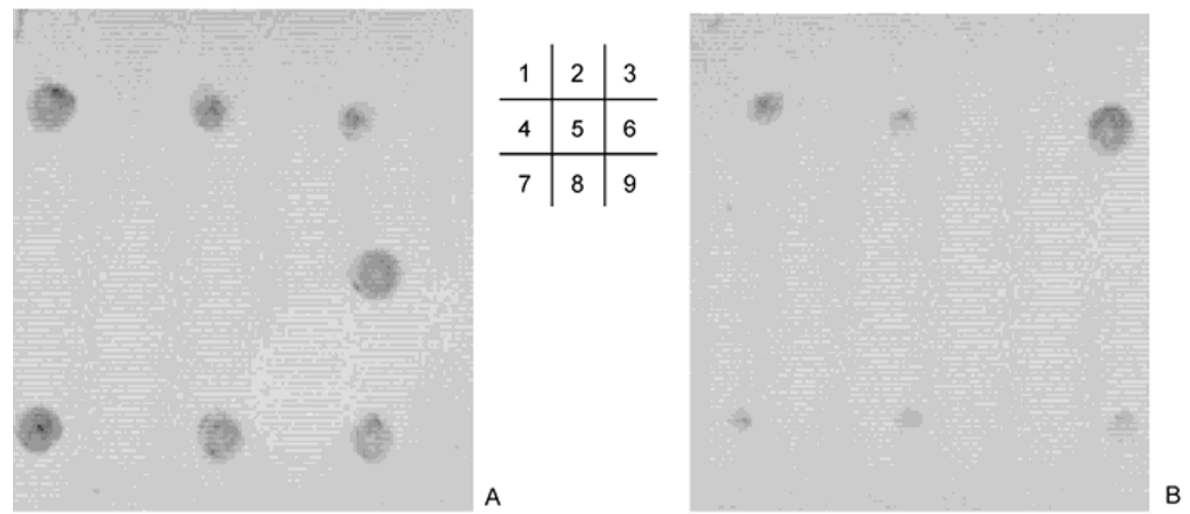

Figure 4 Reverse Northern dot blot of differentially expressed genes. Extracted cDNA bands were reamplified, and aliquots of amplified products were blotted on two membranes as described in Materials and methods. Membranes were hybridized with DIG-labeled cDNAs that were synthesized from total RNA prepared from control (B) and fungus-inoculated A. roxburghii leaves (A). Dots 1-9 are AR-DD17, AR-DD19, AR-DD20, AR-DD38, AR-DD40, AR-23, AR-DD37, AR-DD44, and AR-DD47, respectively.

the sequences were submitted to NCBI databank under the accession numbers shown in Table 1 . The putative functions of the genes were predicted by sequence similarity to genes or proteins of known function in the NCBI database. However, three of them, AR-DD037, AR-DD044 and ARDD047, showed no significant similarity to sequences in GenBank and are potentially unique genes. Of the other two up-regulated genes, AR-DD019 showed high homology to uracil phosphoribosyltransferase of Ricinus communis $(81 \%$ identity), and AR-DD017 showed low sequence identity $(46 \%)$ with a hypothetical protein of Gibberella zeae, a species of fungus. A portion of the cDNA of clone AR-020 showed $100 \%$ homology to a partial sequence of an amino acid transmembrane transporter of A. thaliana. The clone AR-DD023, which was expressed only in fungus-inoculated seedlings, showed $96 \%$ identity with the tRNA-Lys (trnK) gene and the maturase $\mathrm{K}$ (matK) pseudogene of $A$. roxburghii.

\section{Discussion}

The macro-morphology and microstructure of A. roxburghii and Epulorhiza sp. AR-18 indicated that the plant and the fungus formed an endomycorrhiza in the co-culture system in these experiments. Our observations are similar to those reported by Hadley et al. [31] for Spathoglottis plicata B1. We searched for genes with altered expression in the presence of the endophytic fungus, and 7 cDNA fragments were screened from 52 bands. Among the cDNAs isolated, five genes were up-regulated, one gene was down-regulated and one gene was specifically expressed in A. roxburghii inoculated with Epulorhiza sp. AR-18. After comparison of these sequences with those in data banks, we identified four genes with low or high homology to known genes.

The first fragment (AR-DD017) identified in our analysis is a hypothetical protein. The homologs of AR-DD017 identified via BLASTN and BLASTX alignments were not homologous with any known plant proteins, but instead were partially identical to the predicted or hypothetical proteins of some fungi and animals, including G. zeae, Photorhabdus asymbiotica, Nematostella vectensis, and Taeniopygia guttata. Therefore, the exact function of this protein in fungus-promoted plant growth is uncertain.

The second fragment (AR-DD019) identified in our analysis was up-regulated in A. roxburghii inoculated with AR-18: it encodes a uracil phosphoribosyltransferase, for which there are homologs in many plants, including Ricinus communis, Nicotiana tabacum, Zea mays, and Arabidopsis thaliana. Uracil phosphoribosyltransferases (UPRTs; EC 2.4.2.9) are involved salvaging pyrimidines by catalyzing the formation of uridine monophosphate (UMP) from uracil and phosphoribosylpyrophosphate [32]. UPRTs have been described as non-essential, energy-saving enzymes. However, it was reported recently that uracil salvage is of major importance for plant development [33]. The inability to salvage uracil caused a light-dependent dramatic pale-green to albino phenotype, dwarfism, and the inability to produce viable progeny in loss-of-function mutants. Plastid biogenesis and starch accumulation were affected in all analyzed tissues, with the exception of stomata [33]. A single nuclear gene, UPP, encodes the protein, which is targeted to plastids and accounts for almost all UPRT activity in Arabidopsis [33,34]. Previous research found that some endophytic fungi isolated from the roots of orchids had a remarkable growth-promoting effect $[5,10]$. In the present work, the expression of a gene encoding UPRT of $A$. roxburghii was enhanced after co-culturing with AR-18. This illustrates that the capacity for uracil salvage was increased and plastid biogenesis was effectively promoted in A. roxburghii. These data suggest that the endophytic fungus may promote the growth and development of $A$. roxburghii via the enhancement of UPRT gene expression.

The other fragment (AR-DD020) identified in our analy- 
Table 1 Sequence homologies of differentially expressed A. roxburghii cDNA fragments found in NCBI sequence database

\begin{tabular}{|c|c|c|c|c|c|c|c|}
\hline \multirow{2}{*}{ DD-clones } & \multirow{2}{*}{$\mathrm{Bp}$} & \multirow{2}{*}{$\begin{array}{c}\text { GenBank } \\
\text { EST-accessions }\end{array}$} & \multirow{2}{*}{ BLAST hits } & \multirow{2}{*}{$\begin{array}{c}\text { GenBank accessions of } \\
\text { hits }\end{array}$} & \multirow{2}{*}{ BLAST scores } & \multicolumn{2}{|c|}{ Positive scores } \\
\hline & & & & & & (aa) & $(\%)$ \\
\hline AR-017 & 410 & GR410423 & $\begin{array}{l}\text { Hypothetical protein } \\
\text { (Gibberella zeae) }\end{array}$ & XP_391017 & 7.5 & $15 / 32$ & 46 \\
\hline AR-019 & 347 & GR410424 & $\begin{array}{c}\text { Uracil phosphoribosyl- } \\
\text { transferase (Ricinus com- } \\
\text { munis) }\end{array}$ & EEF32516.1 & $8 \times 10^{-23}$ & $99 / 122$ & 81 \\
\hline AR-020 & 307 & GR410425 & $\begin{array}{l}\text { Amino acid transmem- } \\
\text { brane transporter (Ara- } \\
\text { bidopsis thaliana) }\end{array}$ & NP_177862.1 & 0.074 & $15 / 15$ & 100 \\
\hline AR-023 & 311 & GR410426 & $\begin{array}{c}\text { tRNA-Lys (trnK) gene } \\
\text { and maturase K (matK) } \\
\text { pseudogene, (Anoectochi- } \\
\text { lus roxburghii) }\end{array}$ & EU817409 & $2 \times 10^{-124}$ & $88 / 92$ & 96 \\
\hline
\end{tabular}

sis was down-regulated by AR-18. This gene has nucleic acid sequence similarity to the amino acid transmembrane transporter of A. thaliana. In plants, amino acids play fundamental roles in a multitude of processes, including protein synthesis, hormone metabolism, cell growth, production of metabolic energy, nucleotide synthesis, nitrogen metabolism, and urea biosynthesis [35]. In multicellular organisms, many nitrogenous compounds are transported between cells. As mediators of this process, amino acid transporters have been physiologically characterized in plants. Many studies suggest that there are multiple transporters that differ in their substrate spectrum, transport mechanism (i.e., ions used in cotransport), and tissue specificity [36-38]. The nitrogen metabolic pathway is very complicated: some of the reactions are catalyzed by multiple enzymes in different cellular locations, and the known amino acid transporters can be grouped into five superfamilies [35,39]. Therefore, the reduced expression of an amino acid transmembrane transporter in the presence of Epulorhiza sp. AR-18 suggests that it may be a small part of a global mechanism by which the endophytic fungus Epulorhiza sp. AR-18 controls the transcriptional state of a set of genes.

The fourth fragment (AR-DD023) identified in our analysis was expressed only in seedlings inoculated by Epulorhiza sp. AR-18: sequence alignment predicted that it encodes a putative maturase $\mathrm{K}$ (matK) protein. This enzyme is encoded by $\mathrm{tRNA}^{\text {Lys }}$ introns in higher plant chloroplasts and by freestanding open reading frames in the residual plastid genomes of non-photosynthetic plants. The function of the enzyme is in the splicing of multiple group II introns [40]. These nuclear maturase-like proteins may be imported into organelles to function in group II intron splicing and/or they may have other cellular functions. Nuclear-encoded maturases could regulate organellar gene expression and may reflect a step in the evolution of mobile group II introns into spliceosomal introns [40,41]. Because maturase-encoding group II introns are present in plant mitochondria and chloroplast genomes, it is likely that the open reading frames of nuclear maturases were transferred from an organelle to the nucleus, as has been documented for other organellar genes $[42,43]$. Thus, the nuclear-encoded maturase could poten- tially function as part of a common splicing apparatus for multiple organelle group II introns. The transfer of group II intron maturases to the nucleus may have a role in regulation of organellar gene expression; that is, it may link the splicing of one or more organellar introns to global signals that regulate gene expression in response to the cellular energy state or environmental stimuli [44]. The fact that the growth and development of a plant is improved by a symbiosis with an endophytic fungus suggests that fungus-induced changes in plant growth may involve interactions between fungal movement proteins and plant proteins.

In conclusion, we surveyed putative genes playing roles in the growth promotion of $A$. roxburghii during its symbiotic relationship with the endophytic fungus, Epulorhiza sp. AR-18. We identified several novel fungus-responsive genes. Further studies are required to confirm their functions by expressing the full-length sequence of each gene. The full-length sequences of these fragments will provide valuable data for the identification of the complete A. roxburghii transcriptome. Also, they will provide new molecular resources to study the growth promotion and symbiotic relationships of the endophytic fungus with A. roxburghii. These results also showed that the differential display technique is a useful tool for analyzing the molecular mechanism by which endophytic fungi promote growth of the Orchidaceae.

This work was supported by the National Natural Science Foundation of China (Grant Nos. 31070300, 31170314 and 31100265), the Chinese Postdoctoral Science Fund (Grant No. 20080440328), the Natural Science Foundation of Chongqing (Grant No. CSTC2008BB5410), and the Educational Committee Science \& Technology Foundation of Chongqing (Grant No. KJ090504).

1 He C N, Wang C L, Goo S X, et al. A review of research on chemical composition and pharmacological activities of Anoectochilus roxburghii. Chin Pharm J, 2004, 39: 81-84

2 Huang L Y, Chen T W, Ye Z, et al. Use of liquid chromatographyatmospheric pressure chemical ionization-ion trap mass spectrometry for identification of oleanolic acid and ursolic acid in Anoectochilus roxburghii (wall.) Lindl. J Mass Spectrom, 2007, 42: 910-917

3 Shi C C, Wu Y W, Lin W C. Scavenging of reactive oxygen species and inhibition of the oxidation of low density lipoprotein by the 
aqueous extract of Anoectochilus formosanus. Ameri J Chin Med, 2003, 31: 25-36

4 Wang Y J, Meng Z X, Yu X M, et al. Screening of endophytic fungi promoting growth and development of Anoectochilus roxburghii. Chin Pharm J, 2009, 44: 976-979

5 Chen X M, Guo S X. Effects of four species of endophytic fungi on the growth and polysaccharide and alkaloid contents of Dendrobium nobile. China J Chin Mat Med, 2005, 30: 253-257

6 Látalová K, Baláž M. Carbon nutrition of mature green orchid Serapias strictiflora and its mycorrhizal fungus Epulorhiza sp. Biol Plant, 2010, 54: 97-104

7 Meng Z X, Guo S X, Yu X M, et al. Effect of plant growth regulator on proliferation of axillary buds of Anoectochilus roxburghii. Chin Pharm J, 2008, 43: 1777-1780

8 Guo S X, Chen X M, Yu X M, et al. Investigation on the isolation of mycorrhizal fungi from Anoectochilus roxburghii and its biological activity. Chin Pharm J, 2000, 35: 443-445

9 Tang M J, Meng Z X, Guo S X, et al. Effects of endophytic fungi on the culture and four enzyme activities of Anoectochilus roxburghii. Chin Pharm J, 2008, 43: 890-893

10 Gao W W, Guo S X. Effect of three endophytic fungi on growth of Dendrobium candidum and Anoectochilus roxburghii. Chin Trad Herb Drugs, 2002, 33: 543-545

11 Guan J, Wang C L, Guo S X, et al. Effect of endophytic fungus on the total flavone of Anoectochilus roxburghii. Chin Pharm J, 2008, 43: 1031-1032

12 Chen D Y, Ding Y Z, Guo W Z, et al. Molecular cloning and characterization of a flower-specific class III peroxidase gene in G. hirsutum. Mol Biol Rep, 2009, 36: 461-469

13 Zhou B J, Wang X P, Wang Y J. cDNA cloning, expression, protein purification, and characterization of a novel glyoxal oxidase related gene from Vitis pseudoreticulata. Biol Plant, 2007, 51: 458-466

14 Chen X Q, Wang C G, Zhang Y, et al. Identification and sequence analysis of cDNA fragments relative to ovary development of Cymbidium hybridium after pollination. Biol Plant, 2007, 51: 249-256

15 Zhang J F, Turley R B, Stewart J M. Comparative analysis of gene expression between CMS-D8 restored plants and normal non-restoring fertile plants in cotton by differential display. Plant Cell Rep, 2008, 27: 553-561

16 Zhang F Y, Feng B, Li W, et al. Induction of tobacco genes in response to oligochitosan. Mol Biol Rep, 2007, 34: 35-40

17 Liang P, Pardee A B. Differential display of eukaryotic messenger RNA by means of polymerase chain reaction. Science, 1992, 257: 967-971

18 Liang P, Pardee A B, eds. Differential Display Methods and Protocols. Totowa NJ: Humana Press, 1997

19 Murashige T, Skoog F. A revised medium for rapid growth and bioassays with tobacco tissue cultures. Physiol Plant, 1962, 15: 473-497

20 Currah R S, Zettler L W, McInnis T M. Epulorhiza inquilina sp. nov. from Platanthera (Orchidaceae) and a key to Epulorhiza species. Mycotaxon, 1997, 61: 335-342

21 Zelmer C D, Currah R S. Symbiotic germination of Spirantes lacera (Orchidaceae) with a naturally occurring endophyte. Lindleyana, 1997, 12: 142-148

22 Tang M J, Meng Z X, Yu X M, et al. Effect of endophytic fungi on growth of Anoectochilus roxburghii in vitro culture. Chin Trad Herb Drugs, 2008, 39: 1876-1880

23 Senthilkumar S, Krishnamurthy K V, John Britto S, et al. Visualization of orchid mycorrhizal fungal structures with fluorescence dye using epifluorescence microscopy. Curr Sci, 2000, 79: 1527-1528

24 Chang S J, Puryear J, Cairney J. A simple and efficient method for isolating RNA from pine trees. Plant Mol Bio Rep, 1993, 11: 113-116

25 Zhang H, Zhang R, Liang P. Differential screening of differential display cDNA products by reverse Northern. Method Mol Biol, 1997, 85: 87-93

26 Lu S D, ed. Experimental Technology of Modern Molecular Biology. 2nd ed. Beijing: China Concord Medical Science University Press, 2000. 266-270

27 Liu W Q, Wang B C, Duan C R, et al. A method for isolating functional RNA from callus of Dendrobium candidum contented rich polysaccharides. Colloids Surf B: Biointerfaces, 2005, 42: 259-262

28 Sambrook J, Fritsch E F, Maniatis T, eds. Molecular Cloning: A Laboratory Manual. New York: Cold Spring Harbor, 1989. 669-675

29 Ma M, Tan T K, Wong S M. Identification and molecular phylogeny of Epulorhiza isolates from tropical orchids. Mycol Res, 2003, 107: 1041-1049

30 Wu Y X. The Orchids of China. 2nd ed. Beijing: China Forestry Publishing House, 1993. 255-256

31 Hadley G, Williamson B. Features of mycorrhizal infection in some Malayan orchids. New Phytol, 1972, 71: 1111-1118

32 Islam M R, Kim H, Kang S W, et al. Functional characterization of a gene encoding a dual domain for uridine kinase and uracil phosphoribosyltransferase in Arabidopsis thaliana. Plant Mol Biol, 2007, 63: 465-477

33 Mainguet S E, Gakière B, Majira A, et al. Uracil salvage is necessary for early Arabidopsis development. Plant J, 2009, 60: 280-291

34 Arsène-Ploetze $\mathrm{F}$, Nicoloff $\mathrm{H}$, Kammerer $\mathrm{B}$, et al. Uracil salvage pathway in Lactobacillus plantarum: transcription and genetic studies. J Bacteriol, 2006, 188: 4777-4786

35 Wipf D, Ludewig U, Tegeder M, et al. Conservation of amino acid transporters in fungi, plants and animals. Trends Biochem Sci, 2002, 27: $139-147$

36 Sagné C, Agulhon C, Ravassard P, et al. Identification and characterization of a lysosomal transporter for small neutral amino acids. Proc Natl Acad Sci USA, 2001, 98: 7206-7211

37 Fan R C, Peng C C, Xu X F, et al. Apple sucrose transporter SUT1 and sorbitol transporter SOT6 interact with cytochrome b5 to regulate their affinity for substrate sugars. Plant Physiol, 2009, 150: $1880-1890$

38 Martí M C, Olmos E, Calvete J J, et al. Mitochondrial and nuclear localization of a novel pea thioredoxin: identification of its mitochondrial target proteins. Plant Physiol, 2009, 150: 646-657

39 Lam H G, Coschigano K, Schultz C, et al. Use of Arabidopsis mutants and genes to study amide amino acid biosynthesis. The Plant Cell, 1995, 7: 887-898

40 Mohr G, Lambowitz A M. Putative proteins related to group II intron reverse transcriptase/maturases are encoded by nuclear genes in higher plants. Nucleic Acids Res, 2003, 31: 647-652

41 Mastroianni M, Watanabe K, White T B, et al. Group II intron-based gene targeting reactions in eukaryotes. PLoS ONE, 2008, 3: e3121

42 Palmer J D, Adams K L, Cho Y, et al. Dynamic evolution of plant mitochondrial genomes: mobile genes and introns and highly variable mutation rates. Proc Natl Acad Sci USA, 2000, 97: 6960-6966

43 Daniela A, Katrin P, Jörg K, et al. Evolutionary origin of a plant mitochondrial group II intron from a reverse transcriptase/maturaseencoding ancestor. J Plant Res, 2006, 119: 363-371

44 Belhocine K, Mak A B, Cousineau B. Trans-splicing versatility of the L1.LtrB group II intron. RNA, 2008, 14: 1782-1790

Open Access This article is distributed under the terms of the Creative Commons Attribution License which permits any use, distribution, and reproduction in any medium, provided the original author(s) and source are credited. 